\title{
Model Kemitraan Sekolah Cerdas Bencana Dalam Penanggulangan Bencana Gempa Bumi dan Tsunami di Kota Padang
}

\author{
Firanda Catriona ${ }^{1}$, Ria Ariany ${ }^{2}$, Roni Ekha Putera ${ }^{3}$ \\ 1,2,3 Jurusan Administrasi Publik, Fakultas Ilmu Sosial dan Ilmu Politik Universitas Andalas, \\ Padang, Indonesia
}

\begin{abstract}
Partnership in disaster mitigation is important considering that disaster risk reduction efforts are the responsibility of all parties. This study aims to analyze and describe the partnerships of government, NGOs, and Non-Government organization in disaster smart schools in improving earthquake and tsunami disaster preparedness in school located in the red zone in Padang City. This research is motivated by the city of Padang which is a disaster-prone area. Therefore, the municipal government of Padang has the responsibility to protect its citizens from the threat of disaster. The research design used is a descriptive method with a qualitative approach. This research design is considered capable of explaining this research in depth. The results showed that overall the partnership between BPBD Padang and its partners namely Kogami, Jemari Sakato, POF BPBD West Sumatera, and DRRI, in an effort to improve preparedness in schools has gone quite well. The partnership in this study uses a mutualistic partnership models because the partners are aware of the importan aspects of partnership, namely providing mutual benefit and getting more benefits so that they are able to optimally achieve the goals of Disaster Smart Schools.
\end{abstract}

Keywords: Partnership, Disaster Mitigation, Disaster Smart Schools

\section{Pendahuluan}

Indonesia merupakan negara yang memiliki potensi bencana alam atau gempa bumi cukup tinggi. Menurut Undang-Undang Nomor 24 Tahun 2007 tentang Penanggulangan Bencana, pemerintah adalah pihak yang bertanggung jawab penuh dalam hal mengurangi resiko bencana serta melindungi masyarakat dari dampak bencana yang terjadi. Penanggulangan bencana dilakukan dengan tiga tahap yaitu pra bencana, saat bencana dan pasca bencana.
Dalam tahap prabencana atau sebelum terjadinya bencana, dilakukan mitigasi bencana. Mitigasi bencana adalah upaya dalam meminimalisir resiko bencana yang dapat terjadi sewaktu-waktu (Diyahayu, 2018). Mitigasi bencana di sekolah sangat penting dilakukan guna mendukung peningkatan kesiapsiagaan bencana di sekolah (Taufik, 2016).

Salah satu provinsi yang rawan terkena bencana adalah Sumatera Barat terkhususnya Kota 
Padang. Dari segi geografis, Kota Padang menjadi salah satu kota di Indonesia yang paling rawan bencana. Dari data Badan Nasional Penanggulangan Bencana (BNPB) dalam Indeks Rawan Bencana Tahun 2017 menyebutkan bahwa Kota Padang termasuk tiga Ibukota Provinsi yang memiliki tingkat risiko bencana tinggi terbanyak, salah satu bencana yang paling berisiko adalah gempa bumi. Hal ini dikarenakan Kota Padang berada di kawasan Megathrust Mentawai sehinga terancam kejadian bencana gempa bumi yang besar dengan magnitudo 8-9,3 SR (Simandalahi, 2015). Kejadian bencana gempa bumi berkekuatan 7,6 SR pernah terjadi di Kota Padang dan menimbulkan korban jiwa. Banyaknya korban akibat gempa tersebut disebabkan kurangnya pemahaman masyarakat dan pemerintah daerah khususnya anak-anak sekolah akan pentingnya mitigasi bencana untuk menghadapi kondisi terburuk dalam menghadapi bencana, terutama bencana gempa bumi yang berpotensi tsunami .

Pemerintah Provinsi Sumatera

Barat serta pihak swasta telah melakukan berbagai upaya mitigasi bencana dan gempa bumi seperti pelatihan mitigasi. Namun pelatihan tersebut belum mencapai semua kalangan terutama murid-murid sekolah dasar yang belum memiliki pengetahuan dasar gempa dan tsunami serta belum mampu secara mandiri melakukan evakuasi dan mitigasi (Rizky, 2019).

Anak-anak merupakan kelompok rentan yang sulit untuk cepat menyelamatkan diri ketika terjadi bencana. Oleh karena itu Pemerintah Kota Padang perlu memberikan pengetahuan terkait mitigasi bencana agar kepanikan dan korban bencana gempa bumi dari golongan anak-anak dapat ditanggulangi. Hal ini senada dengan yang disampaikan oleh Kepala Bidang Pencegahan dan Kesiapsiagaan BPBD Kota Padang yang menyatakan:

$$
\text { "sebagian wilayah Kota }
$$

Padang merupakan zona merah tsunami. Sebagian besar sekolahnya juga berada di zona merah. Anakanak sekolah merupakan kelompok rentan yang mudah terkena dampak bencana gempa bumi dan tsunami. Makanya kita mempunyai program sekolah cerdas bencana untuk memberikan pengetahuan kepada perangkat sekolah mengenai bencana." (Wawancara dengan Henry selalu Kepala Bidang Pencegahan dan Kesiapsiagaan BPBD Kota Padang pada tanggal 8 September 2020).

$$
\text { Pemerintah Kota Padang }
$$

merancang skema Sekolah Cerdas Bencana guna mempersiapkan diri anak-anak sekolah menghadapi bencana yang sewaktu-waktu dapat terjadi. Hal ini dilakukan agar risiko bencana gempa bumi dan tsunami dapat diminimalisir. Namun, dalam menjalankan program ini Pemerintah Kota Padang dalam hal ini BPBD Kota Padang tidak bisa bekerja sendiri dalam merealisasikan Sekolah Cerdas Bencana. Maka dibutuhkanlah Lembaga Swadaya Masyarakat Kebencanaan di Kota Padang untuk membantu BPBD Kota Padang sebagai pendamping dan fasilitator dalam menyampaikan materi-materi kebencanaan di sekolah-sekolah zona merah di Kota Padang.

Kemitraan antara pemerintah dan LSM Kebencanaan dalam Sekolah Cerdas Bencana guna menghadapi bencana gempa bumi dan tsunami dapat dilakukan dengan beberapa 
indikator kemitraan berikut ini yaitu: adanya tujuan dan manfaat dari kemitraan, kesetaraan dan memiliki peran yang berbeda tergantung tupoksinya masing-masing. Dari semua indikator ini dapat dilakukan oleh pemerintah dan LSM Kebencanaan Kota Padang guna mewujudkan Sekolah Cerdas Bencana. BPBD Kota Padang dalam merealisasikan Program Sekolah Cerdas Bencana dilakukan pada sekolah-sekolah yang berada pada posisi zona merah di Kota Padang yaitu sejumlah 468 sekolah. BPBD mempunyai target 56 sekolah di tahun 2019 pada tingkat Sekolah Dasar dan Sekolah Menengah Pertama (SMP).

Sekolah-sekolah di Kota Padang sudah menerapkan budaya siaga bencana semenjak BPBD Kota Padang dan LSM Kebencanaan di Kota Padang memberikan pelatihan peningkatan kesiapsiagaan di sekolah. Hal ini dibuktikan dengan adanya peta evakuasi sekolah, jalur evakuasi dan titik kumpul yang sudah ditempelkan di dinding sekolahsekolah yang sudah diberikan pelatihan. Berikut salah satu contoh rambu-rambu bencana dan peta evakuai sekolah yang sudah ditempelkan di sekolah-sekolah, seperti pada Gambar 1berikut ini:

\section{Gambar 1 \\ Rambu bencana dan denah evakuasi yang ditempelkan di sekolah-sekolah Kota Padang}

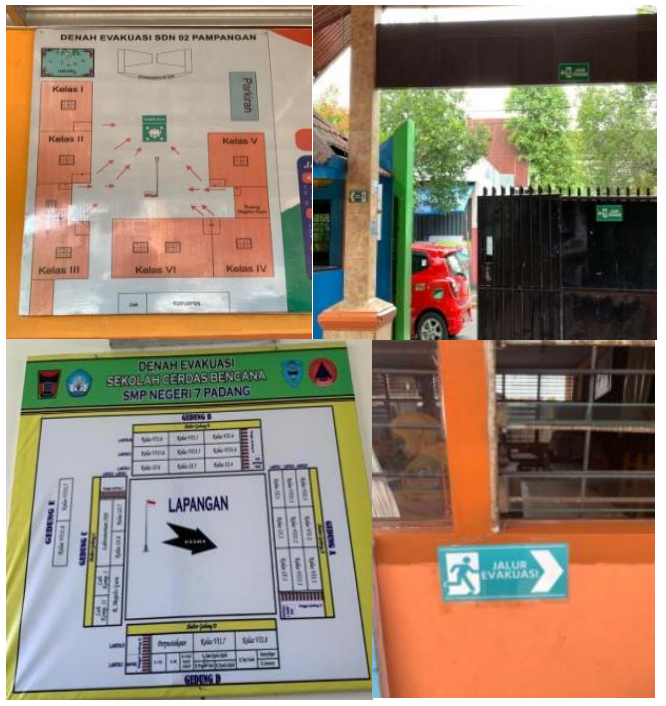

Dari gambar 1 terlihat bahwa sekolah-sekolah di Kota Padang sudah menempelkan rambu-rambu bencana dan denah evakuasi kemana mereka harus pergi saat terjadi bencana gempa bumi dan tsunami. Hal ini dilakukan agar perangkat sekolah lebih sigap ketika terjadi bencana, sehingga akan mengurangi risiko bencana gempa bumi dan tsunami di Kota Padang.

Bentuk kemitraan yang terdapat dalam skema Sekolah Cerdas Bencana adalah BPBD Kota Padang terlebih dahulu merancang skema Sekolah Cerdas Bencana. Setelah skema terbentuk, barulah BPBD Kota Padang meminta bantuan kepada LSM Kebencanaan di Kota Padang untuk bersama-sama merealisasikan Sekolah Cerdas Bencana. Setelah LSM Kebencanaan setuju dengan menugaskan rekan-rekan dari LSM Kebencanaan untuk menjadi tim fasilitator dalam Sekolah Cerdas Bencana, barulah BPBD Kota Padang setelah berdiskusi dengan LSM 
$\begin{array}{llr}\text { Kebencanaan } & \text { Kota } & \text { Padang } \\ \text { memutuskan tim yang akan }\end{array}$ memasuki 56 sekolah-sekolah zona merah di Kota Padang.

Kemitraan antara BPBD Kota Padang dengan LSM Kebencanaan berlangsung sejak tahun 2018. Sebelum menjalin kemitraan, anakanak sekolah belum mengerti bagaimana cara mengevakuasi diri jika terjadi bencana. Namun setelah terjalin kemitraan anak-anak sekolah yang awalnya tidak tahu cara menyelamatkan diri sekarang sudah cerdas ketika terjadi bencana. Anakanak sekolah awalnya banyak yang tidak tahu mengenai rambu-rambu bencana, namun setelah adanya kemitraan mereka sudah paham apaapa saja rambu-rambu bencana sehingga mereka menyelamatkan diri dengan melihat rambu-rambu bencana yang sudah disediakan.

BPBD Kota Padang bertanggung jawab penuh atas terlaksananya kegiatan Sekolah Cerdas Bencana. Pada Peraturan Keputusan Kepala Pelaksana Badan Penanggulangan Bencana Daerah Kota Padang Nomor 223 Tahun 2019 Tentang Sekolah Cerdas Bencana, BPBD Kota Padang dalam merealisasikan Sekolah Cerdas Bencana bermitra dengan LSM (Lembaga Swadaya Masyarakat) Kebencanaan Kota Padang. LSM yang terlibat yakni Pool of Fasilitator (POF) BPBD Sumbar, Komunitas Siaga Tsunami (Kogami), Disaster Risk Reduction Indonesia (DRRI), dan Jemari Sakato di Kota Padang. LSM tersebut adalah lembaga yang bergerak di bidang penanggulangan risiko bencana serta pembangunan berkelanjutan. LSM ini ditunjuk oleh BPBD untuk menjadi pembimbing dan fasilitator dalam pelaksanaan kegiatan pembentukan dan pengembangan Sekolah Cerdas Bencana. Hal ini dikarenakan LSM Kogami, DRRI, POF BPBD Provinsi Sumatera Barat, dan Jemari Sakato merupakan LSM yang berkompeten atau menguasai bidang pengurangan risiko dan penanggulangan bencana. Dengan adanya kesamaan tujuan tersebut maka dipilihlah LSM Kebencanaan ini sebagai mitra dalam melaksanakan Program Sekolah Cerdas Bencana.

\section{Metode Penelitian}

Penelitian ini menggunakan pendekatan penelitian kualitatif dengan tipe deskriptif. Lokasi penelitian bertempat di Kota Padang, Provinsi Sumatera Barat. Teknik pengumpulan data yang digunakan adalah wawancara, observasi dan dokumentasi. Unit analisis pada penelitian ini adalah kelompok yaitu Kogami, Jemari Sakato, DRRI, dan Pool of Fasilitator BPBD Provinsi Sumatera Barat. Metode pengumpulan data dalam penelitian ini yaitu dengan melakukan wawancara dan dokumentasi. Tujuan dari penelitian ini yaitu untuk mendeskripsikan dan mengidentifikasi fenomena atau kejadian yang terjadi di lapangan.

Sementara itu, pihak-pihak lain sebagai mitra pendukung dalam pelaksanaan Program Sekolah Cerdas Bencana ini adalah sebagai berikut: 
Tabel 1

Aktor Pelaksana Dalam Program Sekolah Cerdas Bencana

\begin{tabular}{|c|c|c|}
\hline No. & Aktor & Peran \\
\hline 1 & $\begin{array}{l}\text { Badan } \\
\text { Penanggulangan } \\
\text { Bencana Daerah } \\
\text { Kota Padang }\end{array}$ & $\begin{array}{l}\text { Sebagai penyandang dana. BPBD } \\
\text { Kota Padang bertanggung jawab } \\
\text { penuh sebagai pelaksana } \\
\text { program pemerintah yaitu } \\
\text { Program } \\
\text { Bencana. Sekolah }\end{array}$ \\
\hline 2 & $\begin{array}{l}\text { Dinas } \\
\text { Pendidikan Kota } \\
\text { Padang }\end{array}$ & $\begin{array}{ll}\text { Sebagai instansi yang } \\
\text { membawahi sekolah-sekolah di } \\
\text { Kota Padang. }\end{array}$ \\
\hline 3 & $\begin{array}{l}\text { Kogami Kota } \\
\text { Padang }\end{array}$ & $\begin{array}{l}\text { Sebagai pembimbing dan } \\
\text { fasilitator dalam sosialisasi dan } \\
\text { pelaksanaan Program Sekolah } \\
\text { Cerdas Bencana. }\end{array}$ \\
\hline 4 & $\begin{array}{l}\text { Pool of } \\
\text { Fasilitator } \\
\text { BPBD } \\
\text { Sumbar }\end{array}$ & $\begin{array}{l}\text { Sebagai pemberi fasilitator } \\
\text { terhadap sekolah-sekolah } \\
\text { prioritas dalam Program Sekolah } \\
\text { Cerdas Bencana. }\end{array}$ \\
\hline 5 & $\begin{array}{l}\text { DRRI } \\
\text { Padang }\end{array}$ & $\begin{array}{lrr}\text { Sebagai berperan } & \text { sebagai } \\
\text { pembimbing dan fasilitator } \\
\text { dalam sosialisasi } & \text { dan } \\
\text { pelaksanaan Program } & \text { Sekolah } \\
\text { Cerdas Bencana. } & \end{array}$ \\
\hline 6 & $\begin{array}{l}\text { Jemari Sakato } \\
\text { Kota Padang }\end{array}$ & $\begin{array}{l}\text { Sebagai pembimbing dan } \\
\text { fasilitator dalam sosialisasi dan } \\
\text { pelaksanaan Program Sekolah } \\
\text { Cerdas Bencana. }\end{array}$ \\
\hline
\end{tabular}

Tabel 1.4 menjelaskan bahwa setiap aktor yang terlibat dalam kegiatan Sekolah Cerdas Bencana memiliki peranan masing-masing dan saling berkoordinasi dalam mewujudkan Sekolah Cerdas Bencana. Peran masing-masing lembaga dalam kemitraan Sekolah Cerdas Bencana memiliki keterikatan antara satu sama lain. Pihak-pihak yang bekerja sama mengerti maksud dan tujuan yang dikerjakan yaitu membentuk dan mengembangkan sekolah-sekolah di Kota Padang menjadi Sekolah Cerdas Bencana. Peran dan fungsi dari setiap lembaga tidak dapat dipisahkan karena masing-masing saling bersinergi dalam menjalankan setiap program atau kegiatan.

\section{Hasil dan Pembahasan}

Kemitraan merupakan hubungan timbal balik antar dua pihak atau lebih yang disepakati untuk dilakukan bersama-sama oleh pihak yang saling terkait dan digunakan untuk mencapai tujuan bersama (Sulistiyani, 2004). Sulistiyani model-model kemitraan yaitu Kemitraan Semu, Kemitraan Mutualistik, dan Kemitraan Konjugasi, yang mana peneliti menggunakan teori ini karena fenomena-fenomena yang peneliti temukan dapat dibahas dengan menganalisis menggunakan model kemitraan menurut Sulistiyani. Selanjutnya indikator dari teori Sulistiyani akan dideskripsikan sebagai berikut:

\section{Kemitraan Semu}

\section{a. Kesetaraan}

Program Sekolah Cerdas Bencana, kesetaraan terlihat dari adanya rasa saling menghormati antara pihak-pihak yang bermitra. BPBD Kota Padang dalam menjalankan Program Sekolah Cerdas Bencana membutuhkan masukanmasukan dari mitra kerjanya yaitu Kogami, Jemari Sakato, POF BPBD Provinsi Sumatera Barat, dan DRRI, untuk membuat konsep Sekolah Cerdas Bencana yang sesuai dengan kondisi di Kota Padang. Dalam merancang program ini sesama pihak yang bermitra juga saling menghargai pendapat dan mereka tetap memegang komitmen mereka menjalankan program dengan sebaikbaik mungkin.

Walaupun dalam menjalankan kegiatan, peneliti menemukan adanya 
miss komunikasi antara pihak BPBD Kota Padang dengan POF BPBD Provinsi Sumatera Barat. Namun hal inisudah diselesaikan dengan baik.

\section{b. Keterbukaan}

BPBD Kota Padang dalam menjalankan Sekolah Cerdas Bencana menerapkan prinsip keterbukaan. Semua informasi telah diberikan oleh BPBD Kota Padang terkait Program Sekolah Cerdas Bencana kepada pihak-pihak yang bermitra dan juga kepada perangkat sekolah. Ini dilakukan agar nantinya Program Sekolah Cerdas Bencana ini dapat berjalan sesuai dengan yang diinginkan dan agar tidak ada pihak yang melenceng dalam menjalankan kegiatan Sekolah Cerdas Bencana.

Keterbukaan informasi ini menjelaskan apa-apa saja yang harus dilakukan dan batasan-batasan oleh fasilitator dalam menyampaikan materi. Dengan adanya keterbukaan informasi ini, pihak-pihak yang bermitra mengerti dan paham dengan tugas dan tanggung jawab mereka sebagai fasilitator.

\section{c. Manfaat Bersama}

Kemitraan dalam Sekolah Cerdas Bencana memberikan banyak manfaat bagi para aktor yang terlibat salah satu manfaatnya yaitu dapat menyalurkan ilmu atau pengetahuan yang mereka dapatkan kepada sekolah-sekolah yang berada pada zona merah di Kota Padang. Fasilitator yang ditunjuk pun adalah fasilitator yang sudah dilatih terlebih dahulu sehingga dalam penyampaian materi kepada anak-anak sekolah akan mudah dimengerti oleh mereka. Manfaat Sekolah Cerdas Bencana bagi pihak-pihak yang bermitra sangat besar sekali. Manfaat paling utama yang mereka dapatkan adalah pengetahuan mereka mengenai kebencanaan semakin bertambah, mereka dapat menjalin relasi yang lebih luas, dan dapat mengamalkan ilmu yang sudah mereka dapatkan di tempat lain.

Berdasarkan beberapa indikator dan kutipan hasil wawancara yang sudah peneliti paparkan, dapat disimpulkan bahwa Kemitraan dalam Sekolah Cerdas Bencana Guna Penanggulangan Bencana Gempa Bumi dan Tsunami di Kota Padang tidak menggunakan pola kemitraan semu. Hal ini dikarenakan BPBD Kota Padang dan pihak-pihak yang dilibatkan sama-sama mengetahui manfaat dari kemitraan yang dilakukannya.

\section{Kemitraan Mutualistik}

\section{a. Manfaat}

Dalam kemitraan Sekolah Cerdas Bencana, manfaat dari adanya kemitraan tersebut tidak hanya dirasakan oleh para aktor yang bermitra tetapi juga dirasakan oleh warga sekolah terutama guru dan anak-anak sekolah. Salah satu manfaat yang dirasakan oleh anakanak sekolah ialah mereka mengerti dengan bencana dan cara-cara mengevakuasi diri ketika bencana terjadi.

Manfaat yang ditimbulkan dari adanya Program Sekolah Cerdas Bencana bagi penerima program dalam hal ini Kepala Sekolah, Guru, dan anak-anak sekolah yaitu mereka lebih paham mengenai bencana, mereka lebih dapat meningkatkan kesiapsiagaan diri ketika terjadi bencana, dan juga hal ini bisa mengurangi dampak terjadinya korban bencana gempa bumi dan tsunami.

\section{b. Tujuan}

Perumusan tujuan dalam
kemitraan adalah atas dasar 
kesepakatan bersama oleh semua aktor yang terlibat. Dalam penentuan tujuan utama dari kemitraan dalam Sekolah Cerdas Bencana di Kota Padang adalah ditentukan terlebih dahulu oleh BPBD Kota Padang selalu penanggungjawab dalam hal kebencanaan. Kemudian ketika LSM Kogami, Jemari Sakato, POF BPBD Provinsi Sumatera Barat, DRRI, dan juga anak-anak sekolah akan melakukan kegiatan mitigasi bencana, mereka melakukan diskusi dengan BPBD terlebih dahulu. Sehingga nantinya tujuan dari kemitraan mitigasi bencana yang ditentukan oleh berbagai aktor tersebut dapat dipahami bagi semua aktor. Dan perumusan tujuan tersebut atas dasar kesepakatan bersama dari para aktor yang terlibat.

\section{c. Status}

Status dalam Kemitraan Sekolah Cerdas Bencana dapat dilihat dari kewenangan yang dimiliki oleh BPBD Kota Padang selaku penanggung jawab penuh dalam Program Sekolah Cerdas Bencana dan Lembaga Swadaya Masyarakat yang ditunjuk memiliki kewajiban dalam memberikan materi mengenai kebencanaan kepada sekolah-sekolah yang ditunjuk oleh BPBD Kota Padang.

BPBD Kota Padang memiliki status yang lebih tinggi dibandingkan dengan pihak-pihak yang terlibat dalam fasilitator Sekolah Cerdas Bencana. Pihak-pihak yang terlibat dalam fasilitator di kemitraan Sekolah Cerdas Bencana memiliki status yang setara dan memiliki kewajiban dan tanggung jawab yang sama dalam menjalankan kegiatan Sekolah Cerdas Bencana. Kesetaraan ini terlihat dari pembagian tim yang adil, pembagian tugas yang sama rata, dan informasi yang diberikan pun sama. Semuanya setara dalam hal hak maupun kewajiban dan tanggung jawab dalam pencapaian tujuan bersama

\section{d. Peran}

Peran dalam Kemitraan Sekolah Cerdas Bencana di Kota Padang dimuat dalam aturan Keputusan Kepala Pelaksana Badan Penanggulangan Bencana Daerah Kota Padang Nomor 223 Tahun 2019 Tentang Sekolah Cerdas Bencana. Dengan adanya aturan ini, peran setiap pihak yang bermitra tertuang jelas dan juga pembagian sekolah kepada masing-masing LSM juga sudah jelas. Dalam aturan Keputusan Kepala Pelaksana BPBD ini memuat nama setiap fasilitator yang terlibat dalam pelaksanaan kegiatan Sekolah Cerdas Bencana serta kedudukannya dalam tim untuk kegiatan Sekolah Cerdas Bencana.

Berdasarkan beberapa indikator dan kutipan hasil wawancara yang sudah peneliti paparkan, dapat disimpulkan bahwa Kemitraan dalam Sekolah Cerdas Bencana Guna Penanggulangan Bencana Gempa Bumi dan Tsunami di Kota Padang menggunakan Model Kemitraan Mutualistik. Hal ini dikarenakan BPBD Kota Padang dan pihak-pihak yang bermitra yaitu Kogami, Jemari Sakato, POF BPBD Provinsi Sumatera Barat, dan DRRI, sama-sama menyadari aspek pentingnya melakukan kemitraan yaitu saling memberikan manfaat dan mendapatkan manfaat lebih sehingga akan mampu mencapai tujuan secara optimal. Dari pihak BPBD Kota Padang sebagai penanggung jawab penyelenggaraan Program Sekolah Cerdas Bencana dapat merealisasikan Program Sekolah Cerdas Bencana dan 
sekaligus

kesiapsiagaan

meningkatkan anak-anak dilingkungan sekolah. Dari pihak yang bermitra yaitu Kogami, Jemari Sakato, POF BPBD Provinsi Sumatera Barat, dan DRRI, dapat membagikan ilmu yang didapat oleh para fasilitator untuk memberikan pemahamanan mengenai bencana kepada anak-anak sekolah. Selain itu, manfaat bagi sekolah yaitu kepala sekolah, guru, dan anak-anak sekolah sudah dibekali materi dan tahu apa yang harus dilakukan jika sewaktuwaktu terjadi bencana gempa bumi dan tsunami.

\section{Kemitraan Konjugasi}

\section{a. Saling Percaya}

Saling percaya dalam kemitraan Sekolah Cerdas Bencana adalah bagaimana BPBD Kota Padang menaruh kepercayaan kepada rekanrekan mitra dari Kogami, Jemari sakato, POF BPBD Provinsi Sumatera Barat, DRRI, akan menjalankan kegiatan Sekolah Cerdas Bencana dengan sebaik-baik mungkin. Begitu pula dengan rekan-rekan mitra percaya dengan BPBD Kota Padang akan menjalankan program dengan sebaik-baik mungkin.

BPBD Kota Padang dengan pihak-pihak yang bermitra yaitu Kogami, Jemari Sakato, POF BPBD Provinsi Sumatera Barat, dan DRRI saling percaya antara satu dengan lainnya. Hal ini dibuktikan dengan fasilitator yang bekerja dengan BPBD Kota Padang bukan hanya sekali dua kali tetapi sudah sering bekerja sama dan menyelesaikan program-program kebencanaan. Dari sini timbulah komunikasi rutin dan menjalin relasi yang baik. Fasilitator dari Kogami, Jemari Sakato, POF BPBD Provinsi Sumatera Barat, dan DRRI juga membutuhkan BPBD Kota Padang untuk saling bertukar pikiran dan menambah pengetahuan mengenai lingkungan sekitar, untuk bisa diberikan kepada masyarakat agar masyarakat dapat meningkatkan kesiapsiagaannya terhadap bencana.

\section{b. Saling Membutuhkan}

Dalam menjalankan kemitraan Sekolah Cerdas Bencana, BPBD Kota Padang harus saling mengetahui kekurangan dan kelebihan pihak yang bermitra yaitu Kogami, Jemari Sakato, POF BPBD Provinsi Sumatera Barat, dan DRRI. Begitupun sebaliknya Kogami, Jemari Sakato, POF BPBD Provinsi Sumatera Barat, dan DRRI juga harus mengetahui apa kelebihan dan kekurangan dari koordinator program yaitu BPBD Kota Padang. Jika masing-masing pihak sudah mengetahui kekurangan dan kelebihan mitra maka dalam pelaksanaan program akan jelas pembagian tugas dan wewenang dalam melaksanakan Kegiatan Sekolah Cerdas Bencana. BPBD Kota Padang

membutuhkan fasilitator yang kompeten dalam jumlah banyak untuk merealisasikan programnya, para fasilitator dari LSM bencana juga membutuhkan bantuan BPBD Kota Padang untuk mengamalkan ilmu yang sudah mereka dapatkan dan memperluas relasi mereka. Untuk sekolah-sekolah yang berada di zona merah Kota Padang membutuhkan bantuan BPBD Kota Padang dan para fasilitator untuk dapat meningkatkan kesiapsiagaan sekolah terhadap bencana.

\section{c. Saling Memperkuat}

Dalam menjalankan Kegiatan Sekolah Cerdas Bencana, pihak-pihak yang bermitra saling meningkatkan kemampuannya sebagai fasilitator. BPBD Kota Padang dan pihak yang 
bermitra yaitu Kogami, Jemari Sakato, POF BPBD Provinsi Sumatera Barat, dan DRRI, saling memahami perbedaan cara sudut pandang menyampaikan materi dan juga saling menyadari keterbatasan personal sehingga dengan adanya kemitraan ini dapat saling meningkatkan kemampuan dalam kebencanaan.

\section{d. Saling Menguntungkan}

Saling menguntungkan dalam Kemitraan Sekolah Cerdas Bencana ialah dimana BPBD Kota Padang dan pihak yang bermitra yaitu Kogami, Jemari Sakato, POF BPBD Provinsi Sumatera Barat, dan DRRI sama-sama memberikan keuntungan diantara kedua belah pihak. Keuntungan dari pihak BPBD Kota Padang ialah dapat merealisasikan program kebencanaannya, dan juga keuntungan dari pihak yang bermitra dapat menambah pengetahuan sehingga lebih paham dengan keadaan lingkungan sekitar.

\section{Program Sekolah Cerdas} Bencana tidak menggunakan pola kemitraan ini dikarenakan pihak BPBD Kota Padang dalam menjalankan Program Sekolah Cerdas Bencana tetap bertanggung jawab sampai akhir dan tidak menyelewengkan kekuasaan yang dimilikinya. Malahan pihak BPBD Kota Padang yang berusaha menutupi kekurangan salah satu mitra yang kurang berkompeten.. Dalam menjalankan kegiatan Sekolah Cerdas Bencana LSM Kebencanaan di Kota Padang yaitu Kogami, Jemari Sakato, POF BPBD Provinsi Sumatera Barat, dan DRRI, dibagi persekolah dan pertim. Tetapi walaupun dibagi kedalam tim, mereka tetap ada yang mengawasi dan juga mereka tetap berkoordinasi dalam menjalankan kegiatan tersebut.

\section{Kesimpulan}

Berdasarkan pada penjelasan dan temuan analisis diatas, dapat disimpulkan bahwa secara keseluruhan kemitraan yang dilakukan antara BPBD Kota Padang dengan mitra kerjanya yaitu Kogami, Jemari Sakato, POF BPBD Provinsi Sumatera Barat, dan DRRI, dalam upaya peningkatan kesiapsiagaan sekolah sudah berjalan cukup baik.

Kemitraan dalam Sekolah Cerdas Bencana Guna Penanggulangan Bencana Gempa Bumi dan Tsunami di Kota Padang menggunakan Model Kemitraan Mutualistik. Hal ini dikarenakan BPBD Kota Padang dan pihak-pihak yang bermitra yaitu Kogami, Jemari Sakato, POF BPBD Provinsi Sumatera Barat, dan DRRI, sama-sama menyadari aspek pentingnya melakukan kemitraan yaitu saling memberikan manfaat dan mendapatkan manfaat lebih sehingga akan mampu mencapai tujuan secara optimal.

Kejelasan peran dalam Program Sekolah Cerdas Bencana di Kota Padang tertuang dalam Keputusan Kepala Pelaksana Badan Penanggulangan Bencana Daerah Kota Padang Nomor 223 Tahun 2019 Tentang Sekolah Cerdas Bencana. Dalam surat keputusan ini sudah jelas pembagian sekolah dan peran masing-masing pihak yang bermitra

\section{Referensi}

Putera, Roni Ekha. 2018. Mitigasi Pengurangan Risiko Bencana Gempa Bumi Dari Perspektif 
Implementasi Kebijakan. Depok: RajaGrafindo Persada.

Purtintasari, Diyahayu dan Utami Dewi. 2018. Kemitraan

Pemerintah, LSM, Dan Masyarakat Dalam Mitigasi Bencana Erupsi Gunung Merapi Di Desa Argomulyo, Kecamatan Cangkringan, Kabupaten Sleman. Jurnal Administrasi Negara. Universitas Negeri Yogyakarta. Vol. 7 (4) : 514-528

Rizky, Indra Utama, dkk. 2019. Penerapan Dan Sosialisasi Sekolah Siaga Bencana Bagi Anak-Anak Sekolah Dasar Di Kabupaten Agam. Jurnal Fakultas Teknik. UNP. Vol. 5 (4)

Simandalahi, Tiurmaida,. Ahsan,. Prasetyadjati, Ari .2015. Pengetahuan Tentang Isu Pengurangan Risiko Bencana Berbasis Komunitas Kelompok Siaga Bencana Di Kecamatan Padang Barat Kota Padang.The Indonesian Journal of Health Science, Vol 6 (1) .

Sulistiyani, Ambar Teguh. 2004. Kemitraan Dan Model-Model Pemberdayaan, Yogyakarta: Gava Media.

Taufik, Ahmad. 2016. Implementasi Kebijakan Sekolah Siaga Bencana Dalam Membangun Resiliensi Sekolah di SMPN 2 Cangkringan Kabupaten Sleman. Jurnal Kebijakan Pendidikan, Vol 5(4) 408-4018. 